\title{
LAJU MORTALITAS DAN TINGKAT PEMANFAATAN IKAN LAYANG DELES (Decapterus macrosoma) BERDASARKAN DATA DI PPN PEKALONGAN
}

\author{
Menur Puji Astuti*, Suradi Wijaya Saputra dan Wiwiet Teguh Taufani
}

Program studi Manajemen Sumberdaya Perairan Departemen Sumberdaya Akuatik Fakultas Perikanan dan Ilmu Kelautan, Universitas Diponegoro

Jl. Prof. Soedarto, SH, Tembalang, Semarang, Jawa Tengah - 50275, Telp/Fax. +6224 7474698

*Email : pujia0615@gmail.com

\begin{abstract}
ABSTRAK
Ikan Layang merupakan salah satu ikan pelagis kecil yang bernilai ekonomis penting. Penelitian dilakukan pada Agustus-November 2020 Pelabuhan Perikanan Nusantara (PPN) Pekalongan. Penelitian ini bertujuan untuk mengetahui struktur ukuran, $\mathrm{L}_{\mathrm{C} 50 \%}$, mortalitas, tingkat eksploitasi serta aspek reproduksi yang meliputi TKG dan $\mathrm{L}_{\mathrm{m} 50 \%}$. Pengambilan sampel menggunakan metode sistematik random sampling, dilakukan satu kali dalam setiap bulan. Hasil penelitian menunjukkan bahwa struktur ukuran ikan Layang pada kisaran 140-220mm. LC50\% $=186$ mmTL. LC50\% sebesar 186 mmTL. $\mathrm{L}_{\mathrm{m} 50 \%}$ ikan Layang jantan 179,89 mmTL dan betina 181,25 mmTL. TKG ikan Layang jantan maupun betina didominasi TKG III. Koefisien pertumbuhan (K) sebesar 1,93 dan $\mathrm{L}_{\infty}$ sebesar $221 \mathrm{mmTL}$. Mortalitas total $(\mathrm{Z})=4,02$, mortalitas akhibat penangkapan $(\mathrm{F})=2,41$, mortalitas alami $(M)=1,61$ dan tingkat eksploitasi $(E)=0,60$. Berdasarkan data tersebut dapat disimpulkan bahwa ikan layang yang tertangkap di PPN Pekalongan sudah layak tangkap dan dalam status fully exploited.
\end{abstract}

Kata Kunci : Ikan Layang (D. macrosoma), Laju Mortalitas, Tingkat Eksploitasi, PPN Pekalongan

\section{ABSTRACT}

Shortfin scad is one of the small pelagic fish which has important economic value. The research was conducted in August-November 2020 Pekalongan National Fishing Port. This

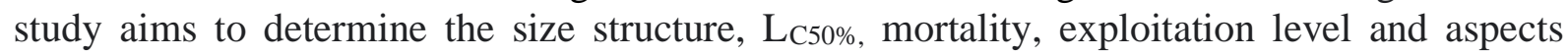

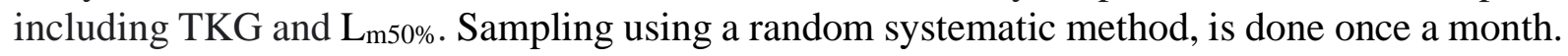
The results showed that the size structure of the fish in the range of 140-220 mmTL a negative allometric growth pattern. $\mathrm{L}_{\mathrm{C} 50 \%}$ of $186 \mathrm{mmTL}$ was greater than the $\mathrm{L}_{\mathrm{m} 50 \%}$ of male Shortfin scad $179.89 \mathrm{mmTL}$ and female $181.25 \mathrm{mmTL}$. TKG of male and female fly fish is dominated by TKG III. The growth coefficient $(\mathrm{K})$ was 1.93 and $\mathrm{L}_{\infty}$ was $221 \mathrm{mmTL}$. Total mortality $(\mathrm{Z})=$ 4.02, fishing mortality $(F)=2.41$, natural mortality $(M)=1.61$ and exploitation rate $(E)=0.60$. Based on these data, it can be concluded that the Shortfin scad caught at PPN Pekalongan are fit to be caught and are in a fully exploited.

Keywords: Shortfin scad (D. macrosoma), Mortalyty, Exploitation Rate, PPN Pekalongan

\section{PENDAHULUAN}

Indonesia merupakan negara maritim yang memiliki potensi perikanan dan kelautan sangat besar. Perairan Utara Jawa merupakan salah satu perairan dengan tingkat pemanfaatan sumberdaya ikan pelagis kecil cukup tinggi. KEPMEN-KP Nomor 45 tahun 2011 menyatakan bahwa pemanfaatan sumber daya ikan pelagis kecil 
di WPP 712 dalam kondisi over fishing, dengan angka tingkat pemanfaatan mencapai 1,40. KEPMEN-KP Nomor 47 tahun 2016 dijelaskan bahwa potensi di WPP712 sebesar 303,886 ton/tahun, dengan tingkat pemanfaatan 0,59 , artinya dalam kategori fully exploited. Menurut Kep-Men KP nomor 50 tahun 2017 potensi ikan pelagis kecil sebesar 364.663 ton/tahun, dengan tingakat pemanfaatan 0.38 , dalam kategori moderate.

Ikan layang merupakan salah satu ikan pelagis kecil yang memiliki nilai ekonomis penting. Ikan Layang yang terdapat di perairan Indonesia ada 5 spesies, yaitu, Decapterus lajang, $D$. ruselli, $D$. macrosoma, D. maruadsi dan D. kurroides. Ikan layang didaratkan di Pelabuhan Perikaanan Nusantara (PPN) Pekalongan terdapat 2 spesies yaitu $D$. macrosoma dan D. ruselii. Ikan Layang memiliki tubuh yang ramping dan memanjang sedikit membulat. (Randongkir et al., 2018)

Hasil tangkapan yang didaratkan di PPN Pekalongan didominasi oleh hasil tangkapan alat tangkap purse seine. Produksi ikan pelagis didominasi oleh ikan Layang (Decapterus sp.), sebesar $46 \%$ atau 8.186 ton dari produksi yang didaratkan di PPN Pekalongan (Anggriani et al., 2016). Hal ini menunjukkan perlu adanya pengkajian lebih lanjut terkait potensi ikan Layang untuk mengetahui tingkat pemanfaatannya, sebagai acuan dalam penyusunan pedoman pengelolaan selanjutnya.

Oleh Sebab itu penelitian yang mengenai laju mortalitas dan tingkat pemanfaatan ikan Layang deles di PPN Pekalongan perlu dilakukan.

\section{MATERI DAN METODE PENELITIAN}

\footnotetext{
Alat

Alat yang digunakan dalam penelitian ini yaitu penggaris dengan ketelitian $1 \mathrm{~mm}$ untuk mengukur panjang ikan, timbangan dengan ketelitian 1 gram untuk mengukur berat ikan, kamera, alat tuis, dan sectio kit untuk membedah ikan.
}

\section{Bahan}

Bahan yang digunakan dalam penelitian ini yaitu sampel ikan Layang (D.macrosoma) yang didaratkan di PPN Pekalongan dan es untuk mengawetkan sampel ikan.

\section{Metode Penelitian}

Metode penelitian yang digunakan metode survei. Pengambilan sampel dengan metode sistematik random sampling, dilakukan 1 kali dalam sebulan selama bulan Agustus-November 2020 di PPN Pekalongan. Pengambilan sampel dilakukan secara acak dari basket kapal dan secara proporsional diambil $10 \%$ per satuan keranjang, dalam satu keranjang berisi $30 \mathrm{~kg}$ maka dalam sekali sampling diambil $3 \mathrm{~kg}$ ikan, pada bulanAgustus mendapat 42 ekor, bulan September 37 ekor, bulan Oktober 42 ekor dan bulan November 45 ekor. Data yang dikumpulkan meliputi data panjang total ikan menggunakan penggaris dengan ketelitian $1 \mathrm{~mm}$ dan pengamatan gonad. Penelitian akan mengkaji stok ikan Layang meliputi struktur ukuran, parameter pertumbuhan, ukuran pertama kali tertangkap (Lc50\%) dan ukuran pertama kali matang gonad $\left(\mathrm{L}_{\mathrm{M} 50 \%}\right)$ untuk mengetahui tingkat pemanfaatan ikan Layang.

\section{Analisis Data \\ Struktur Ukuran}

Metode yang digunakan untuk penentuan ukuran ikan pertama tertangkap menggunakan metode kurva logistik baku, yaitu dengan mengelompokkan atau memplotkan frekuensi kumulatif panjang dari ikan sampel. Analisis data panjang dilakukan dengan membuat kelas frekuensi panjang ikan.

\section{Ukuran Pertama Kali Tertangkap (LC50\%)}

Analisis ukuran pertama kali tertangkap menggunakan metode logistik baku dari Spearman-Karber berdasarkan Saputra (2009), dilakukan dengan membuat tabel frekuensi panjang, kemudian membuat presentase frekuensi dan presentase kumulatif pada setiap kelas panjang, membuat kurva logistik baku. 


\section{Parameter Pertumbuhan}

Pendugaan parameter pertumbuhan yang meliputi panjang asimtotik $\left(\mathrm{L}_{\infty}\right)$, koefisien pertumbuhan (K), dan umur ikan pada saat panjang ikan $0\left(\mathrm{t}_{0}\right)$ dilakukan dengan menggunakan ELEFAN I yang terdapat dalam paket program FiSAT II.

\section{Laju Mortalitas dan Tingkat Eksploitasi}

Persamaan yang digunakan untuk menghitung laju mortalitas yaitu persamaan persamaan empiris Pauly (1980) sebagai berikut:

$$
\begin{aligned}
\mathrm{LnM}= & -0,01520,279 * \operatorname{LnLinf}+0,6543 * \mathrm{LnK} \\
& +0,4634 * \mathrm{LnT} \\
& \text { Mortalitas total }(\mathrm{Z}) \text { diduga dengan }
\end{aligned}
$$
metode Beverton \& Holt (1980) yakni:

$$
\mathrm{Z}=\mathrm{K}\left(\mathrm{Linf}_{-\mathrm{L}}{ }^{\wedge}\right) /\left(\mathrm{L}-\mathrm{L}^{\prime}\right)
$$

Keterangan:

$\mathrm{K} \quad$ : koefisien laju pertumbuhan

L : panjang asimptotik FL

$\mathrm{L}^{\wedge} \quad$ : panjang rata-rata yang tertangkap

L' : batas terkecil ukuran kelas panjang yang tertangkap

Laju mortalitas penangkapan dan eksploitasi dihitung dengan manggunakan rumus sebagai berikut:

$$
\begin{aligned}
& \mathrm{F}=\mathrm{Z}-\mathrm{M} \\
& \mathrm{E}=\mathrm{F} / \mathrm{Z}
\end{aligned}
$$

Keterangan:

$$
\begin{array}{ll}
\mathrm{Z} & \text { : mortalitas total } \\
\mathrm{F} & \text { : mortalitas penangkapan } \\
\mathrm{M} & \text { : mortalitas alami } \\
\mathrm{E} & \text { : laju eksploitasi }
\end{array}
$$

\section{HASIL DAN PEMBAHASAN}

Hasil penelitian menunjukkan bahwa ukuran ikan Layang yang didaratkan di PPN Pekalongan berada pada kisaran 140-220 mm (Gambar 2). Jenis alat tangkap sangat mempengaruhi struktur ukuran ikan Layang yang tertangkap pada suatu perairan tersebut. Menurut Liestianan et al. (2015) menyatakan bahwa ikan Layang (D. macrosoma) di Perairan pekalongan yang ditangkap menggunakan big purse seine memiliki kisaran panjang 105-235 mm. Menurut Omar et al. (2013), menyatakan bahwa ikan Layang di Selat Makassar yang ditangkap menggunakan purse seine dan mini purse seine memiliki ukuran 96 - 219 $\mathrm{mm}$ dan di Teluk Bone ikan Layang yang ditangkap menggunakan purse seine pada kisaran 107-292 mm. Ukuran ikan Layang yang didaratkan di PPN Pekalongan relatif hampir sama dengan perairan lainnya.

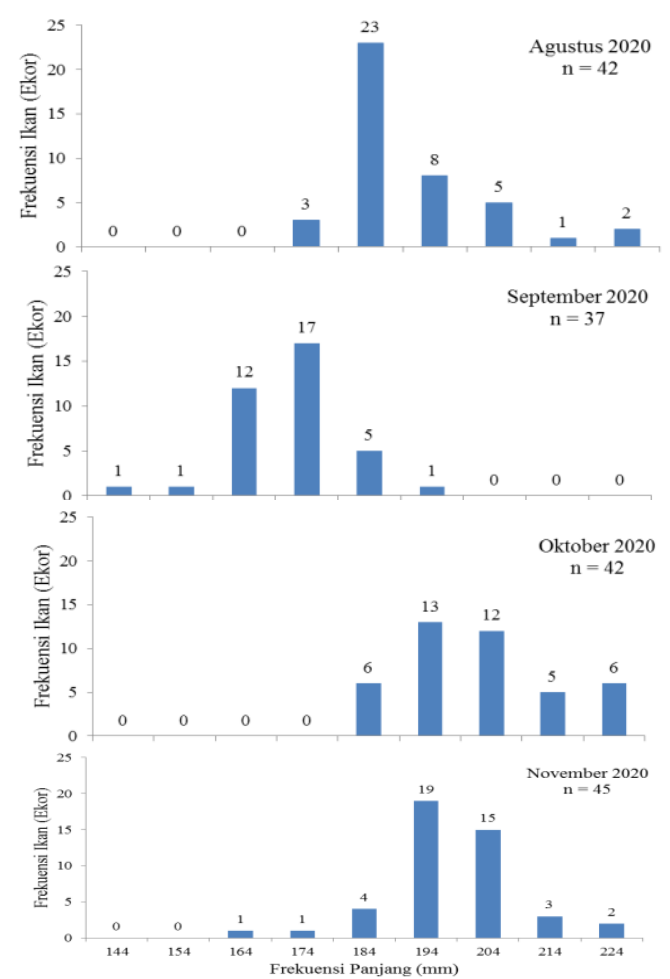

Gambar 1. Frekuensi Panjang Ikan Layang di PPN Pekalongan

Selama Penelitian ukuran ikan pertama kali tertangkap adalah $186 \mathrm{~mm}$. Menurut Pojary et al. (2011) menyebutkan bahwa ukuran pertama kali tertangkap ikan Layang di perairan Mumpai India diduga sebesar 183 $\mathrm{mm}$. Berbeda dengan hasil penelitian Liestiana et al. (2015) bahwa nilai $\mathrm{L}_{\mathrm{C} 50 \%}$ ikan Layang di PPP Sadeng Yogyakarta adalah $255 \mathrm{~mm}$. Widiyastuti dan Zamroni (2017) mengatakan bahwa nilai $L_{C 50 \%}$ ikan layang di perairan Teluk Tomini diduga sebesar $240 \mathrm{~mm}$. LC50\% di PPN Pekalongan lebih kecil dibandingkan dengan $\mathrm{L}_{\mathrm{C} 50 \%}$ di perairan lainnya. Hal tersebut dapar terjadi karna adanya pengaruh dari habitat, persaingan makan dan kondisi lingkungan. Menurut Omar et al. (2013) bahwa ukuran dipengaruhi oleh jumlah organisme dalam 
suatu perairan, ketersediaan makanan dan kondisi lingkungan suatu perairan.

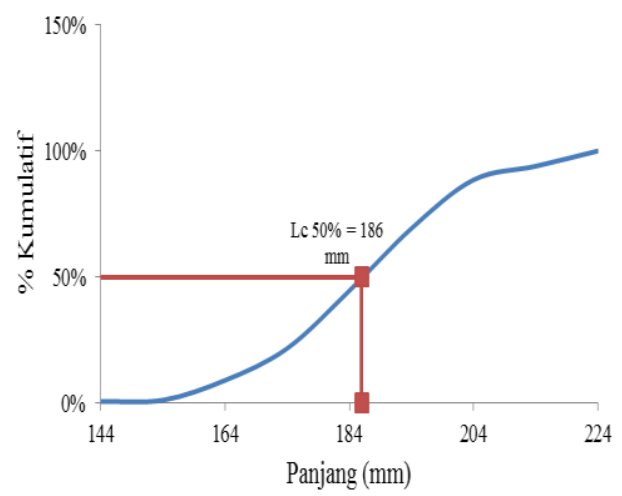

Gambar 2. Ukuran Panjang Pertama Kali Tertangkap

Berdasarkan hasil selama penelitian didapatkan ukuran pertama kali tertangkap (L $\mathrm{L}_{\mathrm{C} 5 \%}$ ) ikan Layang adalah $186 \mathrm{~mm}$. Pojary et al. (2011) bahwa $\mathrm{L}_{\mathrm{C} 50 \%}$ ikan Layang di perairan Mumpai India diduga sebesar 183 mm. Liestiana et al. (2015) bahwa nilai $\mathrm{L}_{\mathrm{C} 50 \%}$ ikan Layang di PPP Sadeng Yogyakarta adalah $255 \mathrm{~mm}$. Widiyastuti dan Zamroni (2017) mengatakan bahwa nilai LC50\% ikan layang di perairan Teluk Tomini sebesar $240 \mathrm{~mm}$. Nilai $\mathrm{L}_{\mathrm{C} 50 \%}$ digunakan untuk menggambarkan ukuran layak tangkap. Menurut Anjayani et al. (2014) menyatakan apabila nilai $\mathrm{L}_{\mathrm{C} 50 \%}>1 / 2 \mathrm{~L} \infty$ menunjukkan ikan layak tangkap. Hasil penelitian didapatkan $1 / 2 \mathrm{~L} \infty$ yaitu $105,5 \mathrm{~mm}$, sehingga $\mathrm{L}_{\mathrm{C} 50 \%}>1 / 2 \mathrm{~L} \infty$ maka ukuran ikan Layang yang tertangkap sudah layak. Namun, supaya tetap terjamin terjadinya rekrutment maka $\mathrm{L}_{\mathrm{C} 50 \%}>\mathrm{L}_{\mathrm{M} 50 \%}$ (ukuran pertama kali matang gonad).

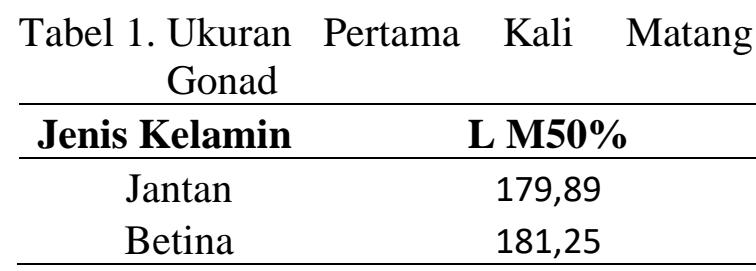

Menurut Senen et al. (2011) bahwa di Teluk Ambon LM50\% ikan Layang jantan 163 $\mathrm{mm}$ dan betina $155 \mathrm{~mm}$. Arniati (2013) dalam Dahlan et al. (2015) mengemukakan di perairan Teluk Bone $\mathrm{L}_{\mathrm{M} 50 \%}$ gonad ikan layang jantan 250 dan betina 245. Berdasarkan uraian tersebut diketahui bahwa Ukuran ikan sudah layak tangkap karena $\mathrm{L}_{\mathrm{C} 50 \%}>\mathrm{L}_{\mathrm{M} 50 \%}$. Menurut Saranga et al. (2019) bahwa apabila ukuran pertama kali tertangkap $\left(\mathrm{L}_{\mathrm{C} 50 \%}\right)$ memiliki nilai yang lebih besar dari ukuran matang gonad (L $\mathrm{L}_{\mathrm{M} 0 \%}$ ) maka dapat diartikan bahwa ukuran ikan yang tertangkap aman untuk kelanjutan kelestariannya.

Berdasarkan uraian tersebut dapat disimpulkan bahwa ukuran pertama kali matang gonad ikan Layang di PPN Pekalongan tidak sama dengan perairan lainnya yang menunjukkan ukuran matang gonad ikan layang betina lebih kecil dibanding ukuran pertama kali matang gonad ikan Layang jantan. Hal ini menunjukkan bahwa ikan layang betina lebih cepat matang gonad dari ikan layang jantan. Diperkuat oleh pernyataan dari Pojary et al. (2015) yang menyatakan bahwa ikan layang betina lebih cepat matang gonad dibandingkan dengan ikan layang jantan.

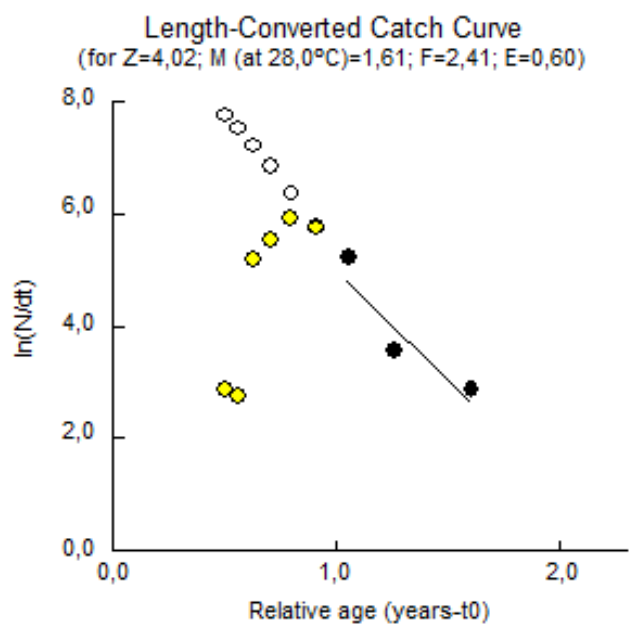

Gambar 3. Kurva Konversi Panjang Ikan Layang Hasil Tangkapan untuk menduga Nilai Mortalitas dan Eksploitasi di PPN Pekalongan

Berdasarkan Gambar 3 dapat diketahui bahwa berdasarkan data selama penelitian diperoleh nilai $\mathrm{Z}$ ikan Layang sebesar 4,02 per tahun. Mortalitas alami pada suhu perairan $28^{\circ}$ sebesar 1,61 per tahun. Mortalitas penangkapan sebesar 2,41 per tahun. Mortalitas penangkapan menunjukkan besarnya laju pennagkapan di perairan tersebut. Mortalitas alami 
disebabkan adanya faktor lingkungan seperti suhu dan salinitas perairan juga faktor predasi dan kompetisi. Diperkuat oleh Nasution (2014) penyebab mortalitas alami adalah penyakit, predator, usia, parasit dan perubahan kondisi lingkungan.

Hasil penelitian Sururi et al. (2017) di Perairan Sorong ikan Layang dengan $\mathrm{M}$ adalah 1,68/tahun, $\mathrm{F}$ adalah 0,82/tahun dan $\mathrm{Z}$ sebesar 2,5/tahun. Berbeda dengan penelitian Suwarni et al. (2015) bahwa di Teluk Bone Sulawesi Selatan, didapatkan nilai Madalah 0,37/tahun, F yaitu 2,07/tahun dan Z sebesar 2,07/tahun. Mortalitas akibat penangkapan lebih tinggi dibanding dengan mortalitas alami.

Hasil penelitian diperoleh nilai ekploitasi (E) = 0,6. Penelitian Suwarni et al (2015) di Teluk Bone didapatkan eksploitasi ikan Layang 0,85. Menurut Desmawanti et al. (2013) penelitiannya di Tanjungpinang mendapatkan nilai eksploitasi sebesar 0,878. Nugroho (2016) menyatakan bahwa bahwa batas tingkat eksploitasi untuk ikan Layang (D.macrosoma) adalah $\mathrm{E}>0,5$.

Berdasarkan hal tersebut maka disimpulkan bahwa mortalitas akibat penangkapan lebih tinggi dibanding dengan mortalitas alami. Tingkat eksploitasi ikan Layang pada tahap fully exploited di beberapa perairan. Apabila eksploitasi pada tingkat fully exploited maka upaya penangkapan harus diperhatikan dengan ketat. Menurut penelitian Nugroho (2016) menyatakan bahwa batas tingkat eksploitasi untuk ikan Layang adalah $\mathrm{E}>\mathbf{0}=0,5$.

\section{KESIMPULAN}

Berdasarkan penelitian yang telah dilaksanakan dapat disimpulkan bahwa ukuran ikan Layang yang didaratkan di PPN Pekalongan sudah layak tangkap. Namun ekploitasi nya sudah masuk dalam tingkat fully exploited, dimana upaya penangkapan sudah mencapai titik optimum sehingga perlu diperhatikan upaya penangkapan yang dilakukan. Laju mortalitas total (Z) sebesar 4,02 per tahun, mortalitas alami (M) sebesar 1,61 per tahun, mortalitas penangkapan $(\mathrm{F})$ sebesar 2,41 per tahun dengan suhu rata-rata perairan $28^{0} \mathrm{C}$ dan nilai $\mathrm{E}$ sebesar 0,6 .

\section{DAFTAR PUSTAKA}

Anggriani. F. D., H. Boesono dan D. A. Ayunita. 2016. Analisis hasil Tangkapan Dan Keuntungan Usaha Penangkapan Purse Seine di Pelabuhan Perikanan Nusantara (PPN) Pekalongan, Jawa Tengah. Diponegoro journal of maquares. 2 (4) : 73-79

Anjayani, L., A. Ghofar dan A. Solichin. 2014. Beberapa Aspek Biologi dan Produksi Hiu Pahitan (Alopias superciliosus) di Perairan Selatan Jawa Tengah. Journal of Maquares. 6 (2): 137-146.

Dahlan. M.A., S.B.A.Omar., J. Tresnawati., M.Nur dan M. T. Umar. 2015. Beberapa aspek Reproduksi Ikan layang (Decapterus macrosoma BLEEKER 1841) Yang Trtangkap Dengan Bagan Parahu Di Perairan Kabupaten Barru, Sulawesi Selatan. Jurnal IPTEKS PSP. 2 (3) : 218-227

Desmawanti. D., T. Efrizal dan A. Zulfikar. 2013. Kajian Stok Ikan Layang (Decapterus ruselli) Berbasis Panjang Berat Dari Perairan Mapur yang Didaratkan Di Tempat Pendaratan Ikan Pelantar KUD Kota Tanjung Pinang. Jurnal Sosek KP. 14 (3): 144162.

Liestiana. H., A. Ghofar dan S. Rudiyanti. 2015. Aspek Biologi Ikan Layang (Decapterus macrosoma) Yang Didaratkan Di PPP Sadeng, Gunung Kidul Yogyakarta. Diponegoro Journal of Maquares 4(4) 10-18

Nugroho. B. A., H. Boesono dan A. N. Bambang. 2013. Fluktuasi Harga Dan Alur Distribusi Ikan Layang Dari hasil Tangkapan Mini Purse seine yang di Daratkan Di Pelabuhan Perikanan Nusantara Pekalongan. 
Jornal of Fisheries Resources Utilization Mnagement and Technologi. 2 (1) :2332

Nugroho. D. 2016. Kondisi Trend Biomassa Ikan Layang (Decapterus spp.) Di Laut Jawa dan Sekitarnya. Jurnal Perikanan Indonesia. 8 (6) : 17-26

Omar, S. B. A., M. A. Dahlan, M. T. Umar, Darmayanti, R. Fitrawati dan S. Kune. 2013. Pertumbuhan Ikan Layang (Decapterus macrosoma Bleeker, 1851) di Perairan Selat Makassar dan Teluk Bone, Sulawesi Selatan. Seminar Nasional Tahunan X Hasil Penelitian Kelautan dan Perikanan. Biologi Perikanan, Makassar

Poojary, N., L.R. Tiwari, dan S. K. Chakraborty. 2011. Stock Assessement of the Indian Scad Decapterus russelli from Mumbai Water. Indian Jurnal of Geo Marine. 40 (5): 680-686.

Poojary, N., L.R. Tiwari, dan S. Sundaram. 2015. Reproductive Biology of the Indian Scad Decapterus russelli (Ruppel, 1830) from Maharashtra Waters, Northwest Coast of India. Journal Marine Biology Assesement India. 57 (1) : 72- 77.

Randongkir. Y.E., F. Simatauw dan T. Handayani. 2018. Aspek Pertumbuhan Ikan Layang (Decapterus macrosoma) Di Pangkalan Pendaratan Ikan Sanggeng Kabupaten Manokwari. Jurnak Sumberdaya Akuatik Indopasifik. 2( 1):87-92
Saranga, R., S. Simau, J. Kalesaran dan M. Z. Arifin. 2019. Ukuran Pertama Kali Tertangkap, Ukuran Pertama Kali Matang Gonad dan Status Pengusahaan Selar boops di Perairan Bitung. Journal of Fisheries and Marine Research, No.3,Vol.1, 67-74.

Senen. B., Sulistiono dan I. Muchsin. 2011. Beberapa Aspek Biologi Ikan Layang Deles (Decapterus Macrosoma) Di Perairan Banda Neira, Maluku. Jurnal Kelautan Perikanan. 5(1) : 17-25

Saputra, S. W. 2009. Dinamika Populasi Ikan Berbasis Riset. Universitas Diponegoro. Semarang. $203 \mathrm{hlm}$.

Sururi. M., Mustasim., F. Hoek dan Anasri. 2017. Laju Eksploitasi Sumberdaya Ikan Layang (Decapterus macrosoma) yang didaratkan di Pangkalan Pendaratan Ikan (PPI) Kota SorongPapua Barat. Jurnal Airaha.6 (1) : 001009

Suwarni., J. Tresnati., M. T. Umar., M. Nur dan Hikmasari. 2015. Pendugaan Beberapa Parameter Dinamika Populasi Ikan Layang (Decapterus macrosoma, Bleeker 1841) Di Perairan Teluk Bone, Sulawesi Selatan. Jurnal Ilmu Kelautan dan Perikanan. 25 (1) : 53-60

Widiyastuti, H. dan A. Zamroni. 2017. Biologi Reproduksi Ikan Malalugis (Decapterus macarellus Cuvier, 1833) di Teluk Tomini. BAWAL. 9 (1) : 63 -71 . 